\title{
Effect of normal stress on the frictional behavior of brucite: application to slow earthquakes at the subduction plate interface in the mantle wedge
}

\author{
Hanaya Okuda ${ }^{1,2}$, Ikuo Katayama ${ }^{3}$, Hiroshi Sakuma ${ }^{4}$, and Kenji Kawai ${ }^{1}$ \\ ${ }^{1}$ Department of Earth and Planetary Science, School of Science, University of Tokyo, Bunkyo, 113-0033 Tokyo, Japan \\ ${ }^{2}$ Department of Ocean Floor Geoscience, Atmosphere and Ocean Research Institute, University of Tokyo, \\ Kashiwa, 277-8564 Chiba, Japan \\ ${ }^{3}$ Department of Earth and Planetary Systems Science, Hiroshima University, Higashi-Hiroshima, 739-8526 Hiroshima, Japan \\ ${ }^{4}$ Research Center for Functional Materials, National Institute for Materials Science, Tsukuba, 305-0044 Ibaraki, Japan
}

Correspondence: Hanaya Okuda (okuda@aori.u-tokyo.ac.jp)

Received: 19 August 2020 - Discussion started: 26 August 2020

Revised: 30 November 2020 - Accepted: 3 December 2020 - Published: 25 January 2021

\begin{abstract}
We report the results of friction experiments on brucite under both dry and wet conditions under various normal stresses $(10-60 \mathrm{MPa})$. The final friction coefficients of brucite were determined to be 0.40 and 0.26 for the dry and wet cases, respectively, independent of the normal stress. Under dry conditions, velocity-weakening behavior was observed in all experiments at various normal stresses. Under wet conditions, velocity weakening was observed at low normal stress (10 and $20 \mathrm{MPa}$ ), whereas velocity strengthening was determined at a higher applied normal stress. Microstructural observations of recovered experimental samples indicate localized deformation within a narrow shear band, implying that a small volume of brucite can control the bulk frictional strength in an ultramafic setting. Among serpentinite-related minerals, weak and unstable frictional behavior of brucite under hydrated mantle wedge conditions may play a role in slow earthquakes at the subduction plate interface in the mantle wedge.
\end{abstract}

\section{Introduction}

Serpentinite is generated by the hydration of ultramafic rocks and has various mineral compositions depending on temperature-pressure conditions of the $\mathrm{MgO}-\mathrm{SiO}_{2}-\mathrm{H}_{2} \mathrm{O}$ system (Evans et al., 2013). As serpentinite has been observed in various important tectonic settings and is consid- ered to contribute to the weakness of serpentinite-dominant areas, the frictional properties of serpentinite have been investigated for several decades (see Guillot et al., 2015, and Hirth and Guillot, 2013, for a review). A large volume of serpentinite is located in mantle wedges in which olivine-rich rock of the upper mantle is hydrated by slab-derived water and composes the subduction plate interface, as suggested by geological and seismological studies (Bostock et al., 2002; Christensen, 2004; Guillot and Hattori, 2013; Hyndman and Peacock, 2003; Kawahara et al., 2016; Kawakatsu and Watada, 2007; Mizukami et al., 2014; Peacock and Hyndman, 1999; Reynard, 2013). Because of the mechanical weakness of serpentinite, the relationship between the presence of serpentinite and the aseismic behavior below the downdip limit of seismogenic zones has been argued (Hyndman and Peacock, 2003; Oleskevich et al., 1999). However, many recent observations have indicated that slow earthquakes, such as episodic tremor and slip (ETS), slow-slip events (SSEs), and low-frequency earthquakes (LFEs), occur at the depth of the mantle wedge in various subduction zones (Audet and Kim, 2016; Obara, 2002; Obara and Kato, 2016; Rogers and Dragert, 2003; Shelly et al., 2006). As slow earthquakes can trigger or be triggered by huge megathrust earthquakes (Obara and Kato, 2016), the nucleation processes of slow earthquakes are important for understanding seismic activities at subduction zones. 
Recent seismological and geological studies have revealed that a layer several hundred meters to kilometers wide is serpentinized and foliated along subduction plate interfaces, and the deformation of this serpentinite layer is likely to relate to slow earthquakes at the depth of the mantle wedge (Bostock et al., 2002; Calvert et al., 2020; DeShon and Schwartz, 2004; Dorbath et al., 2008; Kawakatsu and Watada, 2007; Nakajima et al., 2009; Ramachandran and Hyndman, 2012; Tarling et al., 2019). Within this foliated serpentinite layer, both meta-ultramafic and meta-sedimentary blocks are present, and metasomatic reactions occur at the boundary between these blocks and the serpentinite matrix (Guillot et al., 2015; Tarling et al., 2019). Such a block-in-matrix structure exhibits complex rheological behavior such that shear stress is controlled by both ductile and brittle deformations of block and matrix depending on the strain rate (Fagereng and den Hartog, 2017; den Hartog and Spiers, 2014; Niemeijer and Spiers, 2007; Tarling et al., 2019). Thus, understanding the deformation properties of both the block and matrix is essential to constraining how the subduction plate interface behaves and generates slow earthquakes. This was also underlined by a geological study on the Livingstone Fault, New Zealand (Tarling et al., 2019), which found that the cataclastic slip surface was coated by scaly serpentinite, suggesting that the deformation process of serpentinite is important for brittle deformation and widespread ductile deformation at the subduction plate interface.

In addition, nearly lithostatic pore pressure conditions, which lead to low effective normal stress conditions, have been inferred based on seismic velocity structures at the plate interfaces of several subduction zones where slow earthquakes coincidently occur in regions such as Cascadia, SW Japan, central Mexico, and Hikurangi (Audet et al., 2009; Audet and Kim, 2016; Eberhart-Phillips and Reyners, 2012; Matsubara et al., 2009; Shelly et al., 2006; Song and Kim, 2012). This low effective normal stress condition may be correlated with slow earthquakes because frictional deformation becomes dominant, rather than viscous deformation, in terms of shear strength (French and Condit, 2019; Gao and Wang, 2017). Furthermore, the low effective normal stress condition seems favorable for the nucleation of slow earthquakes (Liu and Rice, 2007, 2009; Rubin, 2008; Segall et al., 2010) and is also consistent with smaller stress drops than regular earthquakes (Ide et al., 2007; Rubinstein et al., 2007, 2008; Schmidt and Gao, 2010). Thus, the frictional properties of serpentinite under low effective normal stress conditions likely play an important role in slow earthquakes at the subduction plate interface near the mantle wedge.

Serpentinite in the mantle wedge is mainly composed of an antigorite-olivine assemblage in warm subduction zones like Cascadia, whereas a brucite-antigorite assemblage dominates in the case of cold subduction zones such as that in NE Japan (Peacock and Hyndman, 1999). Because fluids from subducting slabs have a high $\mathrm{SiO}_{2}$ content, talc is stable in the vicinity of slab-mantle boundaries (Hirauchi et al., 2013; Peacock and Hyndman, 1999). Serpentinite is made up of serpentinite-related minerals, such as antigorite, brucite, and talc, and as those minerals show different frictional behavior, the frictional properties of each mineral should be understood to interpret the mechanical behavior of bulk serpentinite. Many previous experimental studies investigated the frictional properties of antigorite and talc (Hirauchi et al., 2013; Moore et al., 1997; Moore and Lockner, 2007, 2008; Okazaki and Katayama, 2015; Reinen et al., 1994; Sánchez-Roa et al., 2017; Takahashi et al., 2007; Tesei et al., 2018). However, brucite has rarely been considered in previous studies, as it is challenging to detect brucite under natural conditions because of its fine-grained nature (Hostetler et al., 1966). Brucite is not thermodynamically stable when the slab-derived water contains high $\mathrm{SiO}_{2}$ content, and the mantle wedge may undergo silica metamorphism (Manning, 1997; Peacock and Hyndman, 1999). However, geological works on exhumed mantle wedge regions suggest that silica metamorphism has not occurred widely within the shallow mantle wedge because talc zones and metasomatic reactions are often limited in the narrow part near the meta-sedimentary rocks (Angiboust and Agard, 2010; D'Antonio and Kristensen, 2004; French and Condit, 2019; Guillot et al., 2009; Kawahara et al., 2016; Mizukami et al., 2014; Nagaya et al., 2020; Reynard, 2013; Tarling et al., 2019). These observations indicate that the serpentinite layer at the subduction plate interface may contain brucite because of low silica metamorphism as brucite itself has sometimes been found (Kawahara et al., 2016; Mizukami et al., 2014). Hydrothermal experiments also support the finding that $\mathrm{SiO}_{2}$ is effectively consumed and brucite can stably exist with antigorite (Oyanagi et al., 2015, 2020). Although deformation may localize at the metasomatic region (Hirauchi et al., 2013; Tarling et al., 2019), the foliated structure of the serpentinite matrix implies that the serpentinite layer still accompanies some portion of deformation at the subduction plate interface. Furthermore, as brucite is a sheet-structure mineral, which often shows a low friction coefficient due to weak interlayer bonding, its frictional behaviors may play a role in earthquakes at the serpentinite layer (Moore et al., 2001; Moore and Lockner, 2004).

Only a few previous experimental studies under high normal stress conditions of 100 or $150 \mathrm{MPa}$ have been conducted on the frictional properties of brucite. It was shown that brucite has friction coefficients of $0.40-0.46$ (dry) or 0.28 (wet), which are lower than those of antigorite (Moore and Lockner, 2004, 2007; Morrow et al., 2000). Regarding the velocity dependence, significant stick-slip behavior has been observed for dry brucite at both room and high temperature, implying velocity-weakening behavior. Conversely, wet brucite shows velocity-strengthening behavior at room temperature, which gradually changes to velocity weakening with increasing temperature (Moore et al., 2001; Moore and Lockner, 2007). The friction coefficient of a serpentinite gouge can be lowered by approximately $\sim 10 \%-15 \%$ due to 


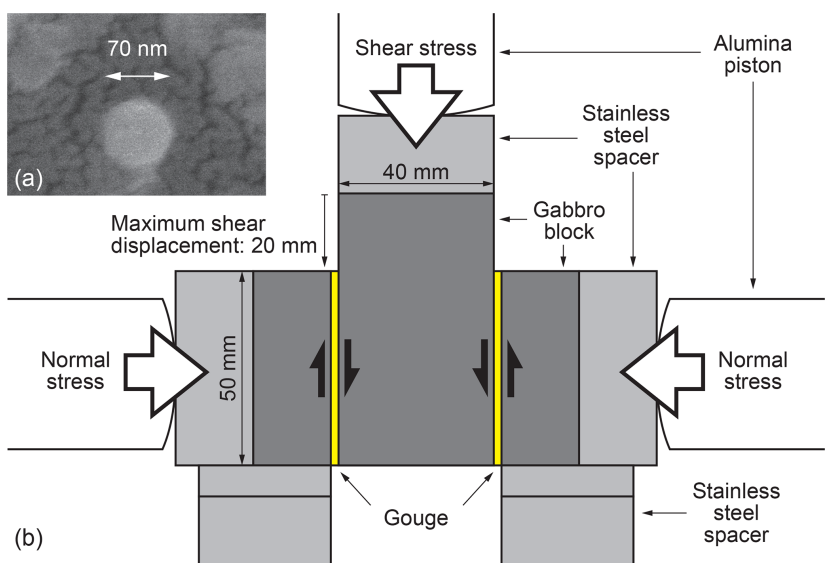

Figure 1. (a) SEM micrograph of synthetic brucite used in this study. (b) Schematic view of the biaxial testing machine used in this study.

the presence of brucite (Moore et al., 2001). The weakness and velocity-weakening behavior of brucite under certain conditions might affect nucleation processes of slow earthquakes at the subduction plate interface in mantle wedges because velocity-weakening behavior is likely to relate to slow earthquakes as proposed in previous studies. Dilatancy hardening in the velocity-weakening system (Rubin, 2008; Segall et al., 2010), slip weakening (Ikari et al., 2013), the transition from a velocity-weakening to velocity-strengthening system at a cutoff velocity (den Hartog et al., 2012; Matsuzawa et al., 2010; Shibazaki and Iio, 2003), and slow stick-slip (Leeman et al., 2016, 2018; Okazaki and Katayama, 2015) are proposed as mechanisms that generate slow earthquakes. Most of them require the velocity-weakening system to nucleate earthquakes, especially for seismologically detected events like LFEs; therefore, the velocity-weakening behavior of brucite can be suggestive of slow earthquakes at the subduction plate interface.

However, the frictional behavior of brucite at low effective normal stress has not been studied in spite of its potential relationship to slow earthquakes. In this study, we experimentally investigated the frictional behavior of brucite at various effective normal stresses ranging from 10 to $60 \mathrm{MPa}$ to understand the effect of brucite on the seismic activities at the subduction plate interface in hydrated mantle wedges.

\section{Methods}

\subsection{Friction experiment}

\subsubsection{Sample preparation}

Brucite nanoparticles with a grain size of $70 \mathrm{~nm}$ chemically synthesized by the FUJIFILM Wako Pure Chemical Corporation were used for the friction experiments to simulate its fine-grained nature (Fig. 1). The synthetic samples had a pu- rity of $99.9 \%$ (data from the FUJIFILM Wako Pure Chemical Corporation).

A biaxial testing machine at Hiroshima University, Japan, was used for all friction experiments in this study (Noda and Shimamoto, 2009). There are two gouge layers between three gabbro blocks (Fig. 1). The surfaces in contact with gouges were roughened before the experiments using carborundum (grit 80 ) to prevent slip between the blocks and sample. All brucite samples were dried in a vacuum oven overnight under $120^{\circ}$ before the experiments. This temperature was selected to remove adsorbed water and prevent the dehydroxylation of brucite into periclase $(\mathrm{MgO})$. For the dry experiments, the brucite powder was quickly sandwiched between the blocks to form the gouge after removing it from the vacuum oven, and the blocks with samples were then put in the testing machine. For the wet experiments, dried brucite was mixed with distilled water before placing it in the gouges and then sandwiched between blocks.

\subsubsection{Experimental procedures}

Normal stress was horizontally applied to the side blocks, and shear stress was applied vertically by pushing the center block downward (Fig. 1). Before applying shear stress, the desired normal stress was applied to the blocks for $1 \mathrm{~h}$ to prevent an effect of the compaction of the gouge during shear deformation (nominally precompaction). For the wet experiments, the blocks and gouges were placed in a tank filled with distilled water for $1 \mathrm{~h}$ under a normal stress of $250 \mathrm{kPa}$ before the precompaction with the desired normal stress such that water-wet conditions were achieved. Note that we did not have a mechanism to prevent the gouge from squeezing out for the wet experiment; therefore, the gouge thickness for wet experiments becomes narrower than that for dry ones. After the precompaction, shear stress was applied with a constant load point velocity of $3 \mu \mathrm{m} \mathrm{s}^{-1}$. Velocity step tests were repeatedly conducted after the shear displacement reached $10 \mathrm{~mm}$ by abruptly increasing the load point velocity to $33 \mu \mathrm{m} \mathrm{s}^{-1}$ and decreasing it to $3 \mu \mathrm{m} \mathrm{s}^{-1}$ after a shear displacement of $1 \mathrm{~mm}$ (Fig. 2). The normal stress conditions of $10,20,40$, and $60 \mathrm{MPa}$ were tested for both the dry and wet cases to study the influence of effective normal stress. In addition, several experiments were conducted with different total shear displacements to investigate the evolution of the gouge microstructure in both the dry and wet experiments (Table 1).

\subsection{Data analysis}

\subsubsection{Mechanical data}

The friction coefficient $\mu$ was calculated from the ratio of the shear stress to the normal stress. Note that cohesion stresses were 0.36 and $0.47 \mathrm{MPa}$ for dry and wet cases, respectively, calculated by linear regression of the shear stress and normal 

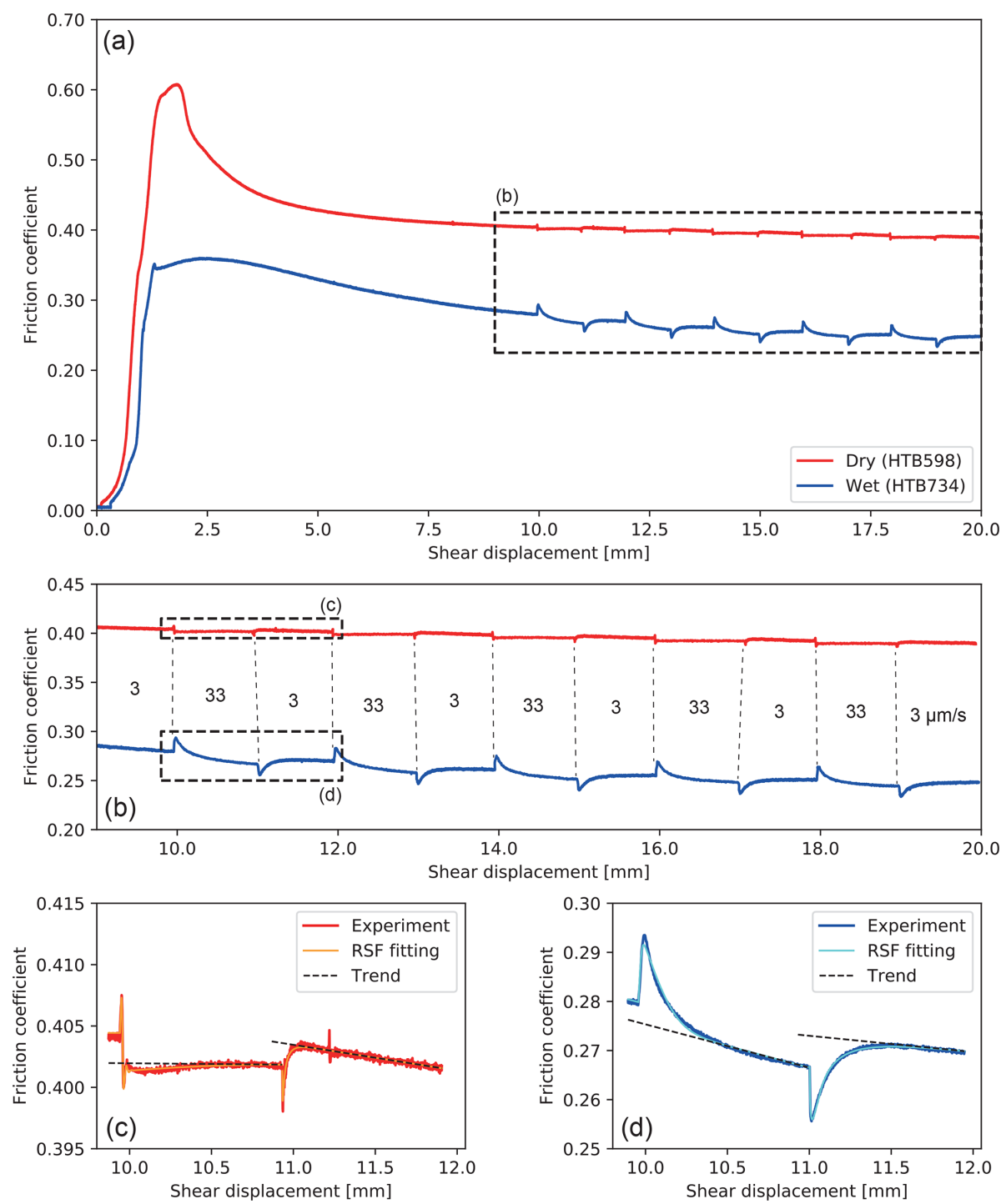

Figure 2. (a) Friction coefficients for dry (HTB598) and wet (HTB734) experiments at a normal stress of 20 MPa. Slip-weakening behavior was observed after the peak under both dry and wet conditions. (b) Enhanced view of velocity step sequences as indicated by the dotted square in (a). The velocities at given shear displacements are displayed between two lines. (c, d) Enhanced views of velocity steps in the squares in (b). Second variables were introduced for upsteps of HTB598 (c).

stress of all the experiments. Because the obtained cohesion stresses were too small to affect the friction coefficients, the cohesion stress was not considered in this study. The shear displacement was corrected using the stiffness of the testing machine $\left(4.4 \times 10^{8} \mathrm{Nm}^{-1}\right)$. The velocity step tests were analyzed using the rate- and state-dependent friction (RSF) law (Dieterich, 1979; Ruina, 1983). Before conducting the following analyses, the friction coefficient vs. the displacement curve was detrended for the slip-weakening trend, which was obtained from the friction data in the second half of each velocity step of $500 \mu \mathrm{m}$ shear displacement. Detrended data were fitted to the following the RSF law:

$\mu=\mu_{0}+a \ln \left(\frac{V}{V_{0}}\right)+b_{1} \ln \left(\frac{V_{0} \theta_{1}}{d_{c 1}}\right)+b_{2} \ln \left(\frac{V_{0} \theta_{2}}{d_{c 2}}\right)$,

where $a, b_{1}$, and $b_{2}$ are nondimensional parameters, $\mu_{0}$ is the steady-state friction coefficient before the velocity step, $V_{0}$ and $V$ are the sliding velocities before and after the velocity step, $d_{c 1}$ and $d_{c 2}$ are the characteristic slip distances, and $\theta_{1}$ and $\theta_{2}$ are the state variables. We estimated the effect of elastic interaction due to the machine stiffness on $V$ using the following relationship:

$\frac{\mathrm{d} \mu}{\mathrm{d} t}=k\left(V_{\mathrm{lp}}-V\right)$, 
Table 1. Summary of the experimental conditions and results.

\begin{tabular}{|c|c|c|c|c|c|c|c|c|}
\hline \multirow[t]{2}{*}{ Experiment } & \multirow[t]{2}{*}{ Condition } & \multirow{2}{*}{$\begin{array}{l}\text { Normal } \\
\text { stress }\end{array}$} & \multirow{2}{*}{$\begin{array}{l}\text { Final shear } \\
\text { displacement }\end{array}$} & \multicolumn{3}{|c|}{ Friction coefficient } & \multicolumn{2}{|l|}{$a-b$} \\
\hline & & & & $\begin{array}{l}\text { Peak } \\
\text { value }\end{array}$ & $\begin{array}{l}\text { Steady } \\
\text { state } \\
(10 \mathrm{~mm})\end{array}$ & $\begin{array}{l}\text { Steady } \\
\text { state } \\
(20 \mathrm{~mm})\end{array}$ & Upsteps $^{\mathrm{a}}$ & Downsteps $^{\mathrm{a}}$ \\
\hline HTB550 & Dry & $20 \mathrm{MPa}$ & $18 \mathrm{~mm}$ & 0.67 & 0.36 & $0.35^{\mathrm{b}}$ & N/A & N/A \\
\hline HTB575 & Dry & $20 \mathrm{MPa}$ & $20 \mathrm{~mm}$ & 0.68 & 0.46 & 0.44 & $-0.0047 \pm 0.0003$ & $-0.0048 \pm 0.0002$ \\
\hline НTB580 & Dry & $10 \mathrm{MPa}$ & $20 \mathrm{~mm}$ & 0.77 & 0.49 & 0.45 & $-0.0024 \pm 0.0004$ & $-0.0014 \pm 0.0003$ \\
\hline ND1 & Dry & $20 \mathrm{MPa}$ & $0 \mathrm{~mm}$ & N/A & N/A & N/A & N/A & N/A \\
\hline НТВ593 & Dry & $20 \mathrm{MPa}$ & $1.5 \mathrm{~mm}^{\mathrm{c}}$ & N/A & N/A & N/A & N/A & N/A \\
\hline НTB595 & Dry & $20 \mathrm{MPa}$ & $2.0 \mathrm{~mm}^{\mathrm{d}}$ & 0.60 & N/A & N/A & N/A & N/A \\
\hline НTB598 & Dry & $20 \mathrm{MPa}$ & $20 \mathrm{~mm}$ & 0.61 & 0.41 & 0.39 & $-0.0010 \pm 0.0002$ & $-0.0009 \pm 0.0002$ \\
\hline HTB601 & Dry & $20 \mathrm{MPa}$ & $10 \mathrm{~mm}$ & 0.65 & 0.42 & N/A & N/A & N/A \\
\hline НTB641 & Dry & $40 \mathrm{MPa}$ & $20 \mathrm{~mm}$ & 0.51 & 0.41 & 0.395 & $-0.0031 \pm 0.0003^{\mathrm{e}}$ & $-0.0020 \pm 0.0004^{\mathrm{e}}$ \\
\hline НTB642 & Dry & $60 \mathrm{MPa}$ & $20 \mathrm{~mm}$ & 0.50 & 0.40 & 0.39 & $-0.0034 \pm 0.0008^{\mathrm{e}}$ & $-0.0012 \pm 0.0006^{\mathrm{e}}$ \\
\hline НТВ734 & Wet & $20 \mathrm{MPa}$ & $20 \mathrm{~mm}$ & 0.35 & 0.28 & 0.25 & $-0.0011 \pm 0.0002$ & $-0.0018 \pm 0.0001$ \\
\hline HTB735 & Wet & $20 \mathrm{MPa}$ & $10 \mathrm{~mm}$ & 0.37 & 0.29 & N/A & N/A & N/A \\
\hline НТВ736 & Wet & $20 \mathrm{MPa}$ & $1.2 \mathrm{~mm}^{\mathrm{c}}$ & N/A & N/A & N/A & N/A & N/A \\
\hline НТВ737 & Wet & $10 \mathrm{MPa}$ & $20 \mathrm{~mm}$ & 0.39 & 0.32 & 0.31 & $-0.0010 \pm 0.0003$ & $-0.0011 \pm 0.0002$ \\
\hline НТВ738 & Wet & $20 \mathrm{MPa}$ & $1.8 \mathrm{~mm}^{\mathrm{d}}$ & 0.34 & N/A & N/A & N/A & N/A \\
\hline НТВ739 & Wet & $40 \mathrm{MPa}$ & $20 \mathrm{~mm}$ & 0.29 & 0.26 & 0.24 & $0.0001 \pm 0.0002$ & $-0.0001 \pm 0.0001$ \\
\hline НTB741 & Wet & $60 \mathrm{MPa}$ & $20 \mathrm{~mm}$ & 0.33 & 0.25 & 0.25 & $0.0012 \pm 0.0001$ & $0.0011 \pm 0.0001$ \\
\hline
\end{tabular}

${ }^{a}$ All parameters $\left(a, b\right.$, and $\left.d_{\mathrm{c}}\right)$ used for the velocity step tests are listed in Table S1. ${ }^{\mathrm{b}}$ Value at a shear displacement of $18 \mathrm{~mm} .{ }^{\mathrm{c}}$ Shear loading was stopped before the peak friction coefficient was reached. ${ }^{\mathrm{d}}$ Shear loading was stopped shortly after the peak friction coefficient was reached. ${ }^{\mathrm{e}}$ Stick-slip behavior was observed, and the $a-b$ value was determined by Eq. (5). NA: not available.

where $V_{\mathrm{lp}}$ is the load point velocity, which was abruptly changed, and $k$ is the system stiffness, which was treated as an unknown parameter (in $\mu^{-1}$ ). The Dieterich (aging) law (Dieterich, 1979; Marone, 1998; Ruina, 1983) was used for the state variable in this study.

$\frac{\mathrm{d} \theta_{i}}{\mathrm{~d} t}=1-\frac{V \theta_{i}}{d_{c i}}, i=1,2$

A MATLAB code, RSFit3000, developed to fit the velocity step and slide-hold-slide tests (Skarbek and Savage, 2019) was used for the analyses of velocity step tests. The second variables $b_{2}, \theta_{2}$, and $d_{c 2}$ (Blanpied et al., 1998) were only introduced when the experimental data were poorly fitted (upsteps of HTB575 and HTB598; Fig. 4); otherwise, $b_{2}$ and $\theta_{2}$ were treated as 0 . The value of $a-b\left(a-b_{1}-b_{2}\right.$ or $a-b_{1}$ ) was then calculated for each step, which describes the instability of the simulated fault: the state of the fault is defined as velocity strengthening and stable when $a-b$ is positive, whereas it is defined as velocity weakening and potentially unstable when $a-b$ is negative. Note that $d_{\mathrm{c}}$ values for the velocity steps whose velocities decreased from 33 to $3 \mu \mathrm{m} \mathrm{s}^{-1}$ (downsteps) are larger than those for the velocity steps whose velocities increased from 3 to $33 \mu \mathrm{m} \mathrm{s}^{-1}$ (upsteps). Because we chose to use the Dieterich (aging) law to fit the RSF law, $d_{\mathrm{c}}$ reflects the diameter of the contact area between grains (Dieterich, 1979; Ruina, 1983). When the load point velocity is $3 \mu \mathrm{m} \mathrm{s}^{-1}$, the lifetime of one contact area is longer than that with a load point velocity of
$33 \mu \mathrm{m} \mathrm{s}^{-1}$. Therefore, the contact diameter, $d_{\mathrm{c}}$, for the load point velocity of $3 \mu \mathrm{m} \mathrm{s}^{-1}$ (downsteps) is larger than that for $33 \mu \mathrm{m} \mathrm{s}^{-1}$ (upsteps). In addition, $d_{\mathrm{c}}$ is also considered to reflect the shear localization (Marone and Kilgore, 1993); when the shear localizes, $d_{\mathrm{c}}$ decreases. Hence, the difference in $d_{\mathrm{c}}$ has qualitative information on the shear localization within the gouge. Although there are still debates on the choice of constitutive laws (Bhattacharya et al., 2015, 2017; Marone, 1998), as all constitutive laws give the same result for $a-b$, we calculated the value of $a-b$ by using separately obtained $a$ and $b$ with the aging law. The focus of this study will be the $a-b$ value because it plays an essential role in the nucleation process of earthquakes. However, other parameters like $d_{\mathrm{c}}$ and stiffness are also important to the nucleation process, and therefore those parameters should be assessed in future studies.

When the system is velocity weakening, which is when $a-b$ is negative, it starts to vibrate automatically (stick-slip) when the system stiffness is lower than a critical stiffness, whereas conditionally stable sliding is achieved when the system stiffness is higher than a critical stiffness. The critical stiffness $k_{\mathrm{c}}$ can be described as follows when quasi-static stick-slip behavior is assumed:

$k_{\mathrm{c}}=\frac{N(b-a)}{d_{\mathrm{c}}}$,

where $N$ is the effective normal stress (Ruina, 1983). Thus, as the effective normal stress $N$ applied to the velocity- 
weakening system increases, the system starts to show stickslip behavior. In other words, the occurrence of stick-slip represents the system being velocity weakening. We determined the $a-b$ value for dry experiments with normal stresses of 40 and $60 \mathrm{MPa}$ by simply comparing the averaged friction coefficients during the stick-slip behavior for two velocities based on the following relationship:

$a-b=\frac{\Delta \mu_{\mathrm{ss}}}{\Delta \ln V}$,

where $\Delta \mu_{\mathrm{ss}}$ and $\Delta \ln V$ are variations in the steady-state friction coefficient and the sliding velocity in the log scale, respectively. In this case, $a, b$, and $d_{\mathrm{c}}$ cannot be determined.

\subsubsection{Microstructure}

In the case of sheet-structure minerals, the friction between basal planes of the crystals (the (0001) plane for brucite) is thought to be significant due to their weak bonding. The shear surfaces of the samples recovered from friction experiments using sheet-structure minerals often show smooth surfaces composed of platy particles aligned parallel to the sliding direction (Moore and Lockner, 2004). Further, according to the experiments with natural samples, the aligned platy particles of interconnected talc were reported to contribute to the low friction coefficient of low-angle normal faults (Collettini et al., 2009).

Because these experiments indicate that the crystal orientation within the gouge has a significant effect on the friction coefficients of sheet-structure minerals, observations of thin sections of recovered samples were conducted after the experiments (Table 1) to investigate the effects of the deformation structures and crystal orientation within the gouges on the frictional behavior. After the experiment, we impregnated the gouge and the blocks with epoxy resin to keep the deformation structures within the gouge. Thin sections parallel to the shear direction and normal to the gouges with a thickness of $30 \mu \mathrm{m}$ were prepared from the impregnated samples. A scanning electron microscope (SEM; JEOL JXA8900; Atmosphere and Ocean Research Institute, University of Tokyo, Japan) was used to observe the microstructures of the gouges. An accelerating voltage of $15 \mathrm{kV}$ and a beam current of $10.0 \mathrm{nA}$ were used for all backscattered electron (BSE) observations. The crystal orientation was determined with a polarizing microscope at the University of Tokyo, Japan.

\section{Results}

\subsection{Mechanical behaviors}

\subsubsection{Friction coefficients}

In general, both dry and wet experiments show high friction coefficients at a shear displacement of 1.5-2 mm (hereafter peak friction coefficients), followed by slip-weakening trends with a shear displacement of about $10 \mathrm{~mm}$ towards steady state (Figs. 2 and S1 in the Supplement). The final friction coefficients at a shear displacement of $\sim 20 \mathrm{~mm}$ for dry and wet conditions under all normal stress conditions were $0.40 \pm 0.04$ and $0.26 \pm 0.03$, respectively (Table 1 ). These final friction coefficients are mostly independent of the applied normal stress (Fig. 3) and consistent with previous experimental results: $0.38-0.46$ and 0.28 for dry and wet brucite, respectively, at an applied normal stress of $100 \mathrm{MPa}$ at room temperature (Moore and Lockner, 2004, 2007). The friction coefficient for dry experiments is also close to the theoretical value of $0.30 \pm 0.03$ (Okuda et al., 2019). Note that the peak friction coefficient of wet brucite at an effective normal stress of $60 \mathrm{MPa}$ is high because of sudden stress drops in the initial stage of the shear displacement (Fig. S1). As these data may include some experimental artifacts, we do not use this peak value for $60 \mathrm{MPa}$ normal stress in this study.

\subsubsection{Velocity dependencies}

For wet experiments, negative $a-b$ values were observed at low normal stresses of 10 and $20 \mathrm{MPa}$ (Fig. 4a and b). However, the $a-b$ values became almost neutral at $40 \mathrm{MPa}$ and positive at $60 \mathrm{MPa}$. A positive $a-b$ value was consistent with previous experiments on wet brucite at an effective normal stress of $100 \mathrm{MPa}$ (Moore et al., 2001; Moore and Lockner, 2007). The $a-b$ values obtained for the upsteps and downsteps insignificantly differ (Fig. $4 a$ and b). In the experiments with normal stress conditions of 20,40, and $60 \mathrm{MPa}$, the constitutive parameter $a$ is almost constant at 0.0054 for both upsteps and downsteps, whereas $b$ decreases from 0.0064 to 0.0042 and from 0.0076 to 0.0040 for upsteps and downsteps, respectively, as the normal stress increases (Fig. 4e and f). Accordingly, we concluded that the decrease in $b$ induces the transition from negative to positive $a-b$. The $d_{\mathrm{c}}$ values at different effective normal stresses insignificantly differ (Fig. 4c and d).

For dry experiments, negative $a-b$ values were obtained at all normal stress conditions (Fig. $4 a$ and $b$ ). When the normal stress was higher than $40 \mathrm{MPa}$, stick-slip behavior was observed. This unstable stick-slip behavior was also reported in the case of a dry experiment at a higher normal stress of $100 \mathrm{MPa}$ (Moore and Lockner, 2004; Morrow et al., 2000). No information on $a, b$, and $d_{\mathrm{c}}$ values for 40 and $60 \mathrm{MPa}$ experiments was obtained because of the stick-slip behavior. As 

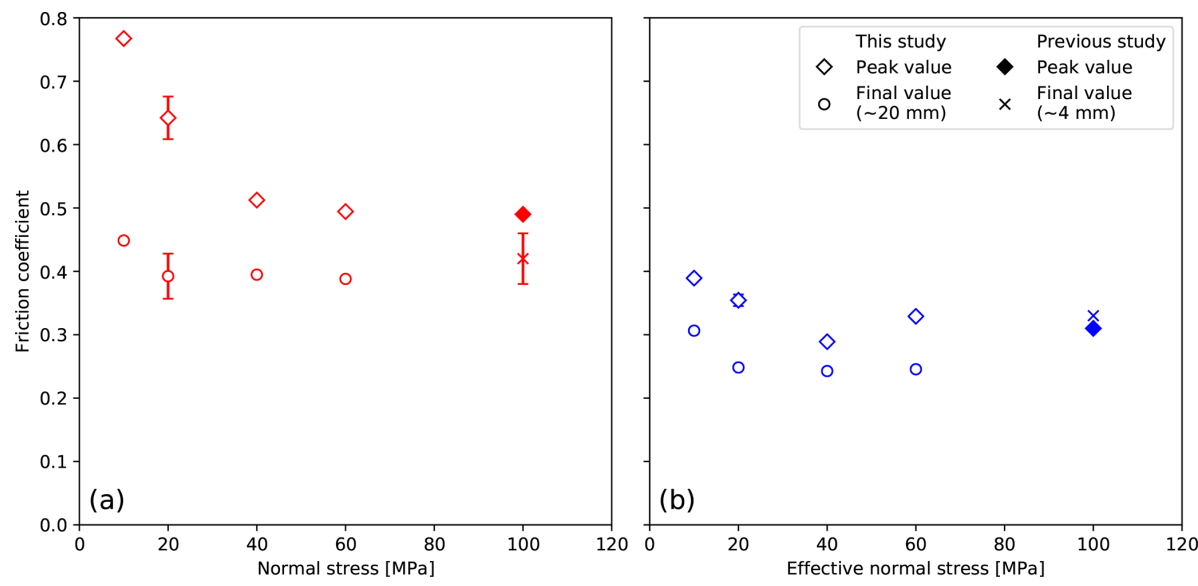

Figure 3. Relationship between normal stress and the peak or final friction coefficients for the dry (a) and wet (b) experiments. Data at a normal stress of $100 \mathrm{MPa}$ were obtained from previous experiments (Moore et al., 2001; Moore and Lockner, 2004, 2007; Morrow et al., 2000). The final friction coefficients do not show a clear trend with normal stress. For this study, the error bar represents the $1 \sigma$ SD among multiple data points. For $100 \mathrm{MPa}$ dry data, the final friction coefficient and the error bar denote the averaged value of stick-slip behavior and its amplitude, respectively. Note that the peak friction coefficient of wet brucite at an effective normal stress of $60 \mathrm{MPa}$ is high because of sudden stress drops in the initial stage of the shear displacement (Fig. S1). As these data may include some experimental artifacts, we do not use this peak value in this study.

shown in wet conditions, larger $d_{\mathrm{c}}$ values were observed for the downsteps (Fig. $4 \mathrm{c}$ and d). Note that the second variables $b_{2}$ and $d_{c 2}$ were introduced in two experiments (HTB575 and HTB598). However, their effects on the earthquake nucleation process, meaning the $a-b$ value, are small because the $b_{2}$ values are much smaller than $b_{1}$, although the $d_{c 2}$ value is much larger than $d_{c 1}$ (Fig. 4e and Table $\mathrm{S} 1$ in the Supplement).

The constitutive parameters $a$ and $b$ as well as the critical slip distance $d_{\mathrm{c}}$ of the dry and wet experiments significantly differ. The $a, b$, and $d_{\mathrm{c}}$ values of the wet experiments are larger than those of the dry experiments (Fig. 4). The critical slip distances $d_{\mathrm{c}}$ of the upsteps and downsteps under wet conditions were 5-15 times and 3-4 times larger, respectively, than those under dry conditions.

\subsection{Microstructure}

\subsubsection{Evolution of deformation structures}

As all samples (both dry and wet) showed a peak value followed by a transition into the steady state, we chose shear displacements before the peak friction coefficient (pre-yield), after the peak friction coefficient (post-yield), and in the steady state $(10 \mathrm{~mm})$ to study the evolution of the deformation structures. Note that the steady state may not be achieved at a shear displacement of $10 \mathrm{~mm}$, but as the final friction coefficients were similar to the friction coefficients at $10 \mathrm{~mm}$ shear displacement, here we used the term "steady state" and considered the idea that the microstructure at $10 \mathrm{~mm}$ shear displacement might be consistent with the steady state. We followed the description of the microstructure of a sheared gouge by Logan et al. (1979). The results for the dry and wet experiments are shown in Figs. 5 and 6, respectively.

Before the shear loading, no shear structure was observed (Fig. 5a). When the shear force was loaded, the Riedel shear propagated in the pre-yield regime, and the gouge thickness decreased rapidly at first (Figs. 5b and 6a). Subsequently, boundary shear started to develop post-yield (Figs. 5c and 6b). In the steady state, boundary shear was created, and the Riedel shear tilted subparallel to the boundary shear (Figs. 5d and 6c). The surfaces of the gabbro blocks were filled with brucite, and the boundary shear was much smoother than the original block surface. These observations are consistent with previous studies (Haines et al., 2013; Kenigsberg et al., 2019, 2020; Logan et al., 1992; Marone, 1998), although a clear $Y$ shear and $P$ foliation were not observed in this study. The gouge thickness remained almost constant post-yield and at steady state, suggesting that the deformation may localize parallel to the shear deformation, i.e., parallel to the boundary shear. The thickness of the entire gouge in the steady state was 400 and $150 \mu \mathrm{m}$ in the dry and wet cases, respectively (Figs. $5 \mathrm{~d}$ and $6 \mathrm{c}$ ). The narrow thickness of the gouge in the wet case may result from leakage of the sample during the experiment, but we did not have a mechanism to prevent the gouge from leaking out. The difference in the entire gouge thickness may not affect the overall frictional characteristics because both dry and wet cases showed Riedel shear development at first, followed by boundary shear development. Observation of grain contact is needed for clarification, but it was not possible in this study because the grains were very small $(70 \mathrm{~nm}$ in diameter $)$. 

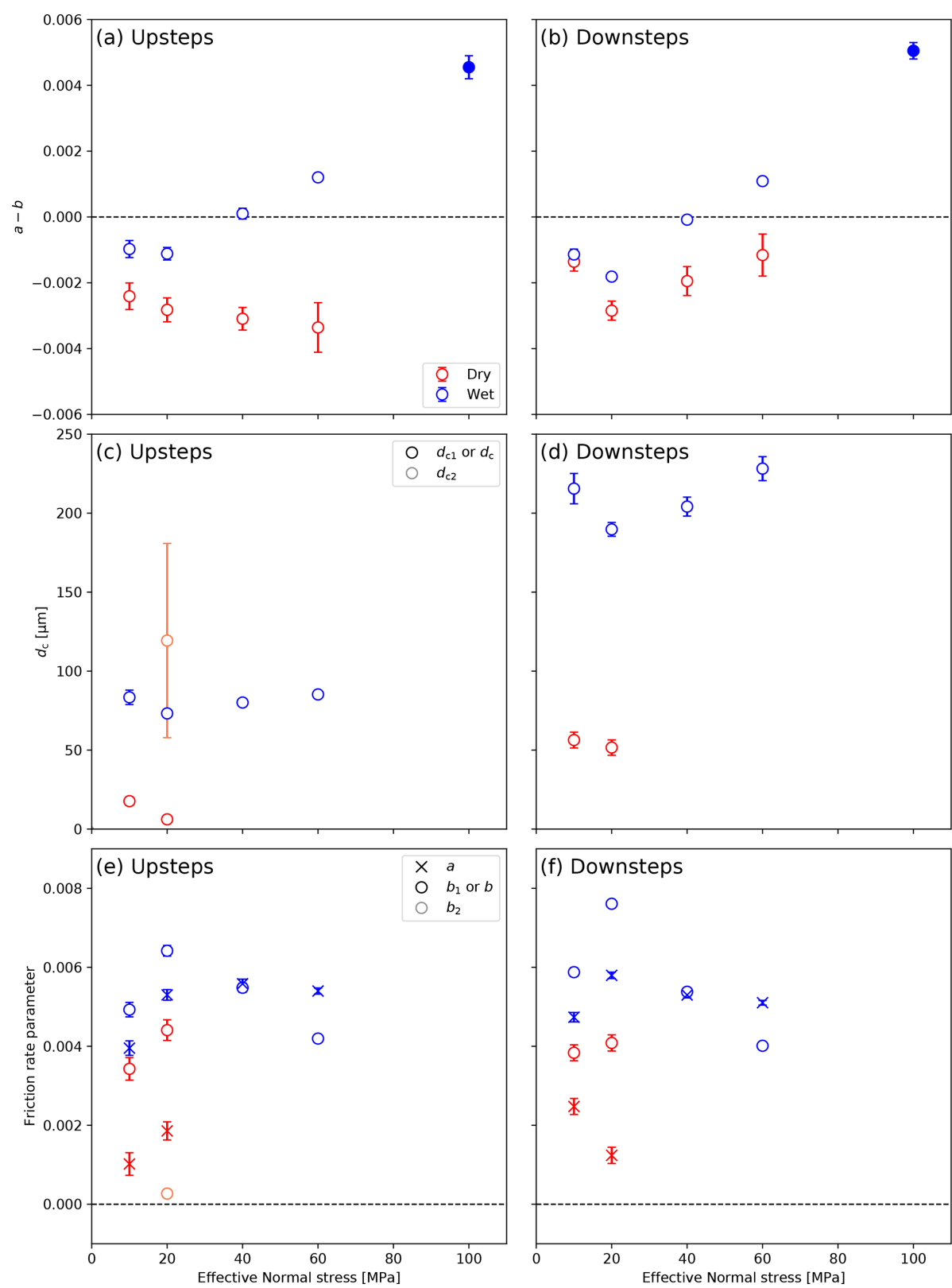

Figure 4. Results of the velocity step tests. Values of $a-b$ for upsteps (a) and downsteps (b), $d_{c}$ for upsteps (c) and downsteps (d), and $a$ and $b$ for upsteps (e) and downsteps (f). The errors represent the $1 \sigma$ SDs of all upsteps or downsteps under each experimental condition, including the errors of the nonlinear least-square fitting processes. The $a-b$ values at a normal stress of $100 \mathrm{MPa}$ were obtained from a previous study (solid symbol; Moore et al., 2001). Because stick-slip behavior was observed in the dry experiments at normal stresses of 40 and $60 \mathrm{MPa}$, $a-b$ values were calculated by Eq. (5) (Sect. 2.2.1). The second variables $b_{2}$ and $d_{c 2}$ were introduced for upsteps of the dry experiments at a normal stress of $20 \mathrm{MPa}$.

\subsubsection{Crystal orientation}

Because brucite has a negative elongation (Berman, 1932) and its birefringence is $0.014-0.020$ (Deer et al., 2013), the interference color of brucite under crossed nicols with a sensitive color plate inserted becomes second-order blue or firstorder yellow when the $c$ axis of brucite is normal or parallel to the $X^{\prime}$ direction of the sensitive color plate, respectively.
In the dry sample (HTB601; Fig. 7a and b), a second-order blue line can be observed parallel to the smooth boundary shear, implying that the basal (0001) plane of the brucite particles is aligned along the boundary shear parallel to the shear direction. We did not observe any alignment along the Riedel shears, suggesting that deformation along the Riedel shears cannot be dominant at the steady state. Based on the magnified view, the brucite particles are oriented within $10 \mu \mathrm{m}$ 

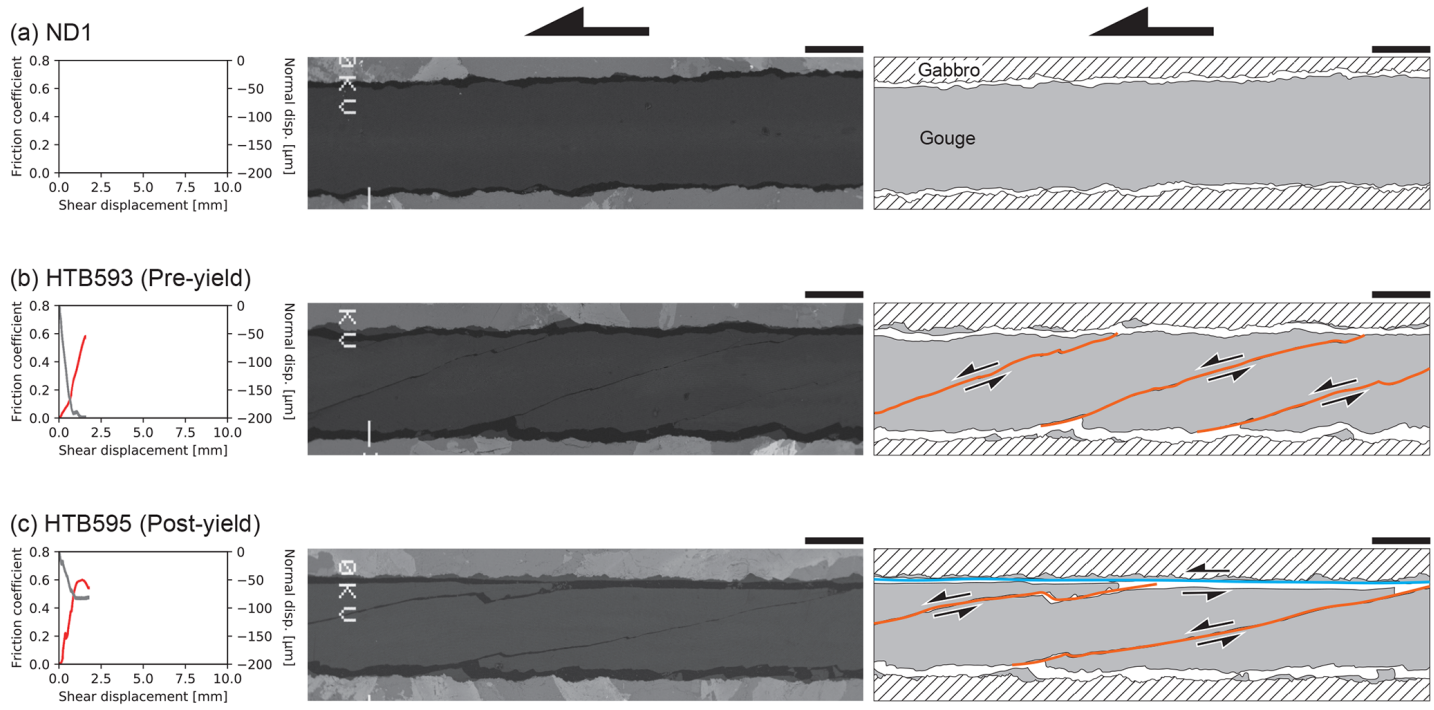

(d) HTB601 (Steady state)
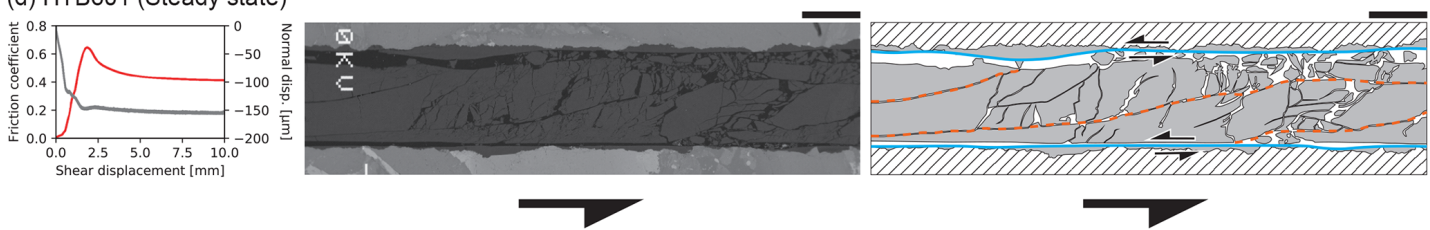

Figure 5. Backscattered electron (BSE) images showing the deformation of gouges (center) and corresponding interpretive sketches (right) of the dry experiments. The friction coefficients and normal displacement are shown in (a-d) using colored and gray lines. The orange lines, blue lines, gray area, hatched area, and white area in the sketches correspond to the Riedel shear, boundary shear, brucite gouge, gabbro block, and epoxy resin, respectively. The orange dotted lines are the Riedel shears, which may not be active. The arrows represent the slip directions. The scale bars represent $200 \mu \mathrm{m}$
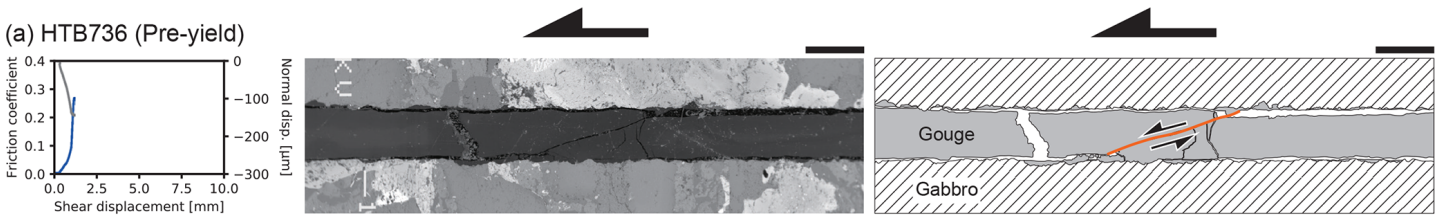

(b) HTB738 (Post-yield)
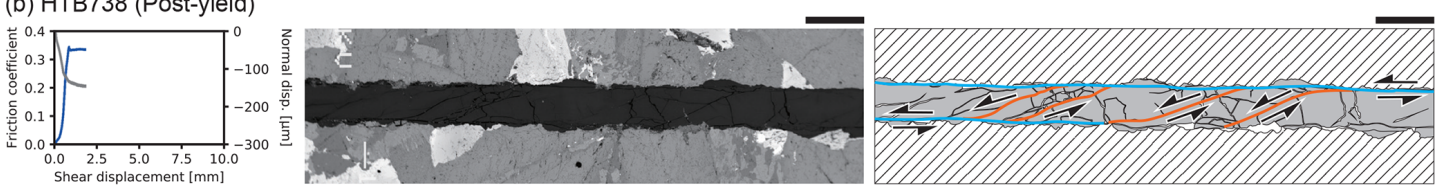

(c) HTB735 (Steady state)
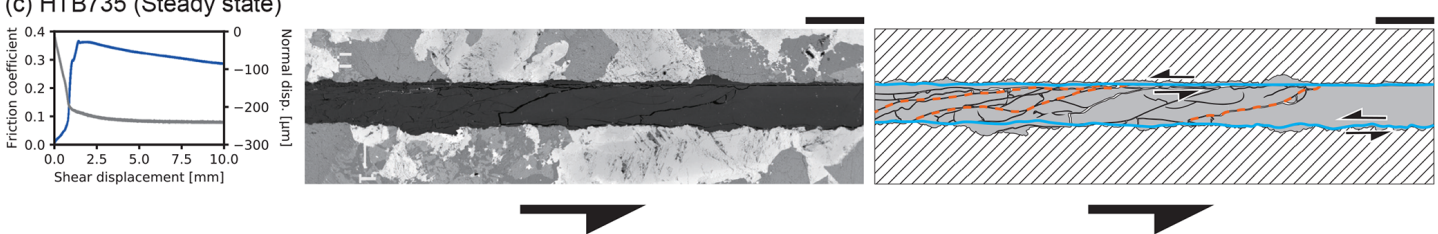

Figure 6. Backscattered electron (BSE) images showing the deformation of gouges (center) and corresponding interpretive sketches (right) of the wet experiments. See Fig. 5 for descriptions. 

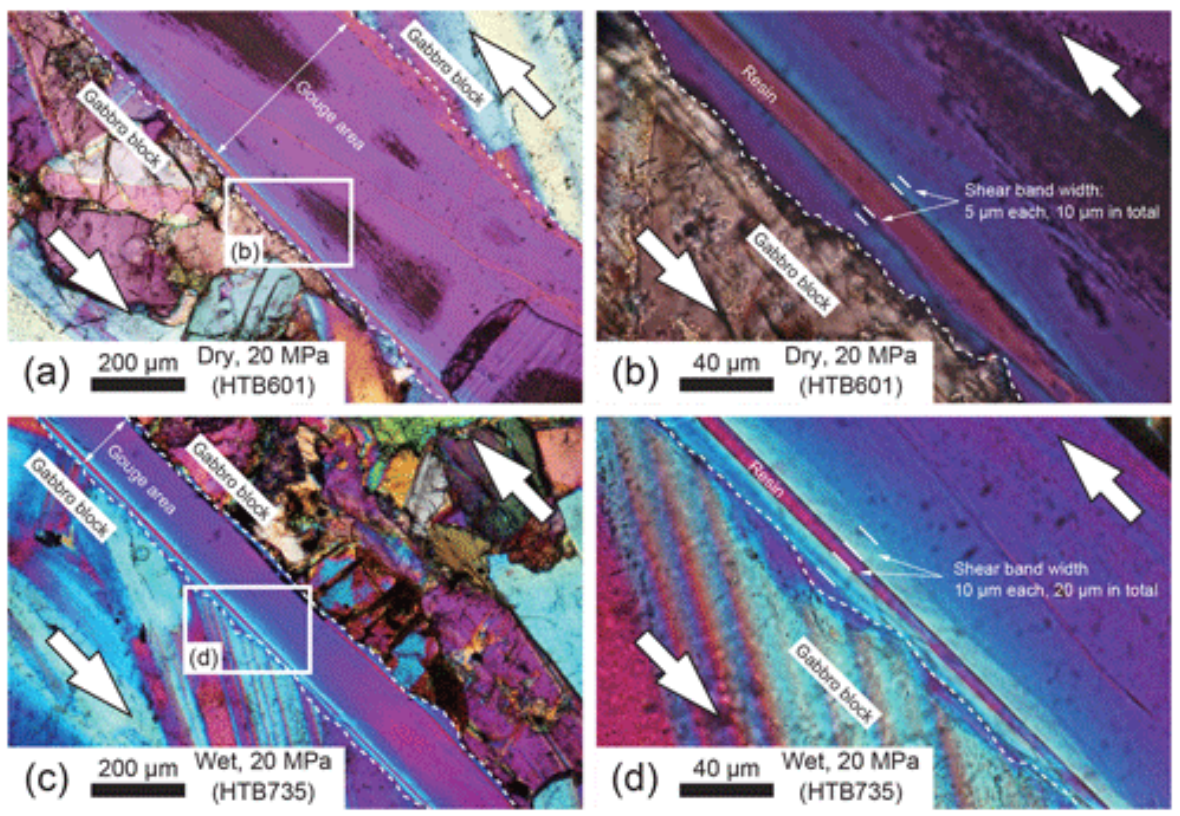

Figure 7. Observation of the crystal orientation using a polarizing microscope under crossed nicols with a sensitive color plate. The arrows indicate the shear direction. The $X^{\prime}$ direction of the sensitive color plate is parallel to the shear direction. (a) Dry experiment with $20 \mathrm{MPa}$ normal stress (HTB601). (c) Wet experiment with $20 \mathrm{MPa}$ normal stress (HTB735). Panels (b) and (d) are magnified views of (a) and (c), respectively. The shear band thicknesses are indicated in the panels. The white dashed line represents the boundary between the gabbro block and the brucite gouge.

around the boundary shear (Fig. 7b). Because the purple area indicates that the brucite particles are randomly oriented, the shear strain can be localized within a thickness of $10 \mu \mathrm{m}$. Hereafter, we call this oriented area the "shear band." In the wet samples, the crystals are also oriented along the boundary shear (Fig. 7c and d). The thickness of the shear band is $20 \mu \mathrm{m}$ (Fig. 7d), which is a little wider than that for the dry experiments. This observation is consistent with the relationship between the shear localization and $d_{\mathrm{c}}$ value (Marone and Kilgore, 1993): the degree of shear localization for the dry sample is higher than that for the wet sample, and $d_{\mathrm{c}}$ for dry sample was smaller than for the wet sample (Fig. 4). Note that detailed transmission electron microscopy is required in future studies to confirm the crystal orientation and shear band thickness, as shown in previous studies (Verberne et al., 2014a; Viti, 2011).

\section{Discussion}

\subsection{Mechanical weakness of a small amount of brucite}

Based on the microstructural observations in Sect. 3.2, the boundary shear is smooth, filling the rough surface of the gabbro block as a "fault mirror" (Siman-Tov et al., 2013). The brucite particles are aligned along the boundary shear, suggesting that the deformation within the narrow shear band is responsible for most of the deformation of the gouge dur- ing the steady state. In addition, the constant gouge thickness during the steady state suggests that gouge deformation occurs parallel to the shear direction, consistent with shear deformation localized within the shear band.

Because previous studies showed that a smooth slip surface reduces the friction coefficient compared to a roughened slip surface (Anthony and Marone, 2005), the development of the smooth boundary shear observed in this study would reduce the friction coefficient with increasing shear displacement (Haines et al., 2013). In addition, the slip between the basal planes of sheet-structure minerals also plays an important role for weak friction because the friction between single crystals of sheet-structure minerals has a lower friction coefficient than that of powdered samples (Horn and Deere, 1962; Kawai et al., 2015; Niemeijer, 2018; Okamoto et al., 2019). Based on the observed alignment of the basal plane of brucite within the shear band, the friction between the basal planes of brucite crystals might enhance the weak friction of brucite. Because the preferred planes of nanoparticles tend to be aligned even when the velocity is low (Verberne et al., 2013, 2014b), nanoparticles could contribute to the slip-weakening behavior. Based on these phenomena, we conclude that the mechanical weakness of brucite observed in this study is likely derived from the smooth boundary shear of fine brucite particles and alignment of the basal plane of brucite parallel to the boundary shear. 
The results of several previous experimental studies showed that the friction coefficient of a mixture of strong and weak materials inversely correlates with the volume of the weak materials (Giorgetti et al., 2015; Logan and Rauenzahn, 1987; Moore and Lockner, 2011; Niemeijer and Spiers, 2007; Shimamoto and Logan, 1981; Takahashi et al., 2007; Tembe et al., 2010). Based on the maximum amount of brucite in serpentinite, which is $\sim 20$ vol. \% (Kawahara et al., 2016; Moore et al., 2001), the expected friction coefficient of the antigorite-brucite mixture is 0.53 , assuming a simple linear mixing law between the wet friction coefficients of 0.6 for antigorite and 0.26 for brucite. This value is not small, but the bulk friction coefficient of the mixture will decrease if weak brucite crystals are interconnected with each other. The microstructural observations showed that the shear band is less than $50 \mu \mathrm{m}$ wide (Sect. 3.2.2; Fig. 7); therefore, a narrow network of brucite can decrease the bulk strength. The results of a recent petrographic study of a hydrated paleomantle wedge revealed brucite thin films parallel to antigorite particles, suggesting the significant role of brucite in the development of the sheared structure of the antigorite-brucite assemblage in the hydrated mantle wedge (Mizukami et al., 2014). Because the maximum thickness of the brucite film in the antigorite-brucite assemblage is several hundred micrometers (Kawahara et al., 2016; Mizukami et al., 2014), which is larger than $50 \mu \mathrm{m}$, brucite has the potential to drastically weaken the bulk strength of serpentinite.

\subsection{Application to the mantle wedge conditions}

When we consider the effect of brucite on the seismic activities in the mantle wedge, the effect of temperature should be taken into account because all our experiments were conducted under room-temperature conditions. According to previous experiments on brucite under hydrothermal conditions in which the temperature was varied, the friction coefficient and the $a-b$ values decrease with increasing temperature (Moore et al., 2001; Moore and Lockner, 2007). Because a nearly neutral $a-b$ value was observed at an effective normal stress of $150 \mathrm{MPa}$ and a temperature of $340^{\circ}$ (Moore et al., 2001), brucite shows unstable behavior under a wide range of temperature-pressure conditions, especially at low effective normal stress. Based on the estimated frictional properties of brucite under mantle wedge conditions, we compared brucite to other mineral phases to interpret the earthquake processes within the mantle wedge (Fig. 8).

In the mantle wedge, ultramafic minerals such as olivine transform into serpentine minerals, such as antigorite, talc, and brucite, due to hydration. In cold subduction zones, such as beneath NE Japan, likely containing brucite under the temperature-pressure conditions of the mantle wedge, the thermodynamically stable mineral assemblages are lizarditebrucite (Liz-Brc) at depths shallower than $50 \mathrm{~km}$ and antigorite-brucite (Atg-Brc) under deeper and warmer conditions (Peacock and Hyndman, 1999). Previous experimen-

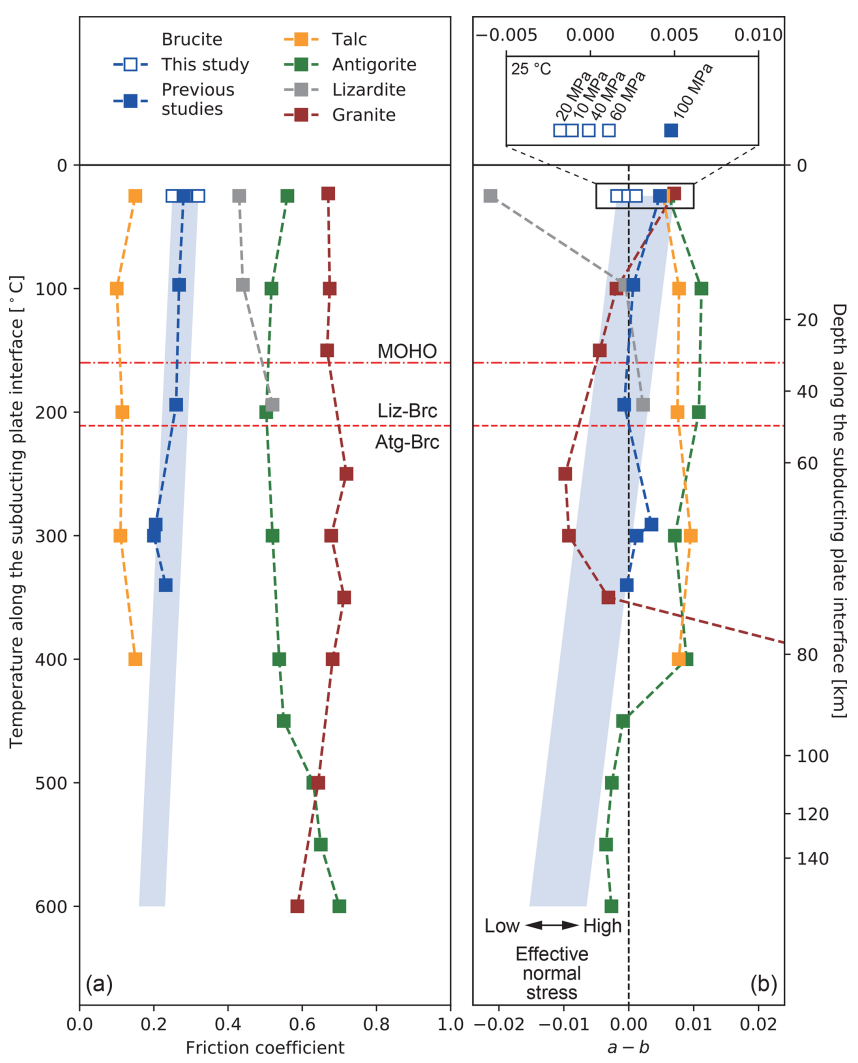

Figure 8. Friction coefficients (a) and velocity dependences (b) of brucite (this study; Moore et al., 2001), talc (Moore and Lockner, 2008), antigorite (Okazaki and Katayama, 2015; Takahashi et al., 2011), lizardite (Moore et al., 1997), and granite (Blanpied et al., 1998). The vertical axes are identical to the temperature gradient along the subduction plate interface in NE Japan (Peacock and Wang, 1999). The upper dash-dotted line represents the typical depth of the Mohorovičić discontinuity (MOHO). The lower dashed line represents the phase boundary between lizardite-brucite (Liz-Brc) and antigorite-brucite (Atg-Brc; Peacock and Hyndman, 1999). The blue shaded areas are the estimated frictional characteristics extrapolated from experimental results. With the decrease in the effective normal stress, the $a-b$ value decreases, as indicated by the arrow. This trend was confirmed at room temperature, as shown in the inset at the top of (b) and Fig. 4.

tal studies on antigorite suggested potential seismic activities due to the unstable frictional behavior of antigorite at high temperatures above $450^{\circ} \mathrm{C}$ (Okazaki and Katayama, 2015; Takahashi et al., 2011) at which crustal (granitic) rock shows stable friction (Fig. 8), whose friction coefficient (0.5-0.7) is not as low as that of brucite (Fig. 8). Although lizardite, which thermodynamically destabilizes at $\sim 200^{\circ} \mathrm{C}$, potentially shows unstable frictional behavior at low temperature (Moore et al., 1997), its friction coefficient is 0.4-0.5, which is lower than that of antigorite but higher than that of brucite (Fig. 8). Therefore, antigorite and lizardite are not preferably deformed if other weaker minerals, such as brucite, are 
present in continuous fault strands in which the deformation localizes.

Another candidate for such a weak mineral stable under mantle wedge conditions is talc. Talc has a low friction coefficient of $0.1-0.2$ at low to high temperatures (Fig. 8); therefore, it might contribute to the creep behavior of the San Andreas Fault (Moore and Lockner, 2008) or weaken the slab-mantle interface (Hirauchi et al., 2013; Hyndman and Peacock, 2003). However, because talc has a stable frictional behavior at any temperature, leading to aseismic creep (Moore and Lockner, 2008; Sánchez-Roa et al., 2017), it cannot nucleate earthquakes. When we consider talc in the mantle wedge, talc is thermodynamically stable at high $\mathrm{Si}$ concentrations and temperature, whereas the mineral assemblage consists of brucite and antigorite when the Si content and temperature are low (Peacock and Hyndman, 1999). Talc was not widely observed in the paleo-mantle wedge exposed in the Shiraga body (central Shikoku, Japan) at temperaturepressure conditions under which the antigorite-brucite system is thermodynamically stable (Kawahara et al., 2016; Mizukami et al., 2014). Although only antigorite stably exists in the antigorite-brucite stability field when the Si content is high, brucite is widely distributed in the Shiraga body ( 10\%-15\%), suggesting low Si metasomatism in the shallow hydrated mantle wedge (Kawahara et al., 2016). Hence, brucite can stably exist within the mantle wedge rather than talc. Although talc is still significantly important for deformation at the subduction plate interface (Hirauchi et al., 2013), the possible occurrence of brucite and its weak and unstable frictional characteristics implies that brucite may be a possible control for the seismic activities at the subduction plate interface in the shallow hydrated mantle wedge.

The results of recent seismological studies showed that plate interfaces in a shallow mantle wedge have a nearly lithostatic pore pressure due to slab-derived water at various subduction zones in SE Japan, Cascadia, central Mexico, and Hikurangi (Audet et al., 2009; Audet and Kim, 2016; Eberhart-Phillips and Reyners, 2012; Matsubara et al., 2009; Shelly et al., 2006; Song and Kim, 2012). Such low effective normal stress conditions are conducive to brittle deformation rather than ductile behavior (French and Condit, 2019; Gao and Wang, 2017). Slow earthquakes in the mantle wedge of various subduction zones (Audet and Kim, 2016; Obara and Kato, 2016) might be induced by low effective normal stress because low effective normal stress conditions are conducive to the nucleation of slow earthquakes (Liu and Rice, 2007, 2009; Rubin, 2008; Segall et al., 2010). As the $a-b$ value of brucite decreases with decreasing effective normal stress, brucite at low effective normal stress possibly causes the nucleation of slow earthquakes in the mantle wedge. On the other hand, an increase in the $a-b$ value at higher stresses was caused by a decrease in the $b$ value (see Sect. 3.1.2), which may be related to the saturation of the real area of contact (Saffer and Marone, 2003). As the $b$ value can be recast as the healing rate in slide-hold-slide experiments (Ikari et al., 2016), wet brucite cannot store strain energy at the high effective normal stress condition. Notably, the possible presence of brucite-free antigorite or talc due to high $\mathrm{Si}$ content in the vicinity of the slab-mantle interface (Hirauchi et al., 2013; Peacock and Hyndman, 1999) might affect the partitioning of deformation (French and Condit, 2019) and the contribution of brucite to the deformation. The mechanisms of nucleation of slow earthquakes are still debated in both theoretical and experimental studies; for example, dilatancy hardening, the transition from a negative to positive $a-b$ value, slip weakening, and slow stick-slip are all considered possible mechanisms (den Hartog et al., 2012; Ikari et al., 2013; Leeman et al., 2016, 2018; Matsuzawa et al., 2010; Okazaki and Katayama, 2015; Rubin, 2008; Segall et al., 2010; Shibazaki and Iio, 2003). As other serpentiniterelated minerals show stable frictional behavior, i.e., positive $a-b$, friction experiments with mixtures of brucite and other minerals like talc and antigorite may provide further information on the generation of slow earthquakes. In addition, the linkage between high pore fluid pressure and effective normal stress is still debated (Hirth and Beeler, 2015; Noda and Takahashi, 2016); therefore, experiments under hydrothermal conditions with high confining pressure and high pore fluid pressure must be conducted in the future.

\section{Conclusions}

In this study, the influence of effective normal stress on the frictional characteristics of brucite was experimentally determined under both dry and wet conditions at room temperature. The final friction coefficients of brucite are 0.40 and 0.26 in the dry and wet cases, respectively, independently of the applied normal stress, while the peak friction coefficients are inversely correlated with the applied normal stress. In all dry experiments, velocity-weakening or stick-slip behavior was observed at every normal stress. In the wet experiments, velocity-weakening, velocity-neutral, and velocitystrengthening behaviors were observed at normal stresses of 10 and 20, 40, and $60 \mathrm{MPa}$, respectively. Combined with the previously reported temperature effect, this result suggests that brucite is weak and unstable under a wide range of temperature-pressure conditions. The microstructural observations reveal that a low friction coefficient and slip weakening from the peak to steady-state friction coefficient are due to smooth boundary shear and basal plane orientation parallel to the boundary shear. Because the deformation is concentrated within a narrow shear band with a thickness less than $50 \mu \mathrm{m}$, a small amount of brucite can weaken the bulk strength of the antigorite-brucite assemblage. Compared to other serpentinite minerals, brucite is the only mineral that shows both a low friction coefficient and velocity-weakening behavior. Hence, we conclude that weak, unstable brucite contributes to the nucleation of slow earthquakes in the shallow hydrated mantle wedge. 
Data availability. The results of all experimental data are available in the Supplement.

Supplement. The supplement related to this article is available online at: https://doi.org/10.5194/se-12-171-2021-supplement.

Author contributions. HO conceptualized this study. HO and IK conducted the experiments. HO and HS conducted analyses before experiments. HO carried out formal analyses and microstructural analyses. HO prepared the original paper, which was reviewed and edited by all coauthors. KK was the supervisor. IK, HS, and KK designed the research project.

Competing interests. The authors declare that they have no conflict of interest.

Special issue statement. This article is part of the special issue "Thermo-hydro-mechanical-chemical (THMC) processes in natural and induced seismicity". It is a result of the The 7th International Conference on Coupled THMC Processes, Utrecht, Netherlands, 35 July 2019.

Acknowledgements. We thank two anonymous referees for their careful and constructive reviews. We also thank Yuta Noda and Riho Fujioka for the experiments, Hayami Ishisako for the preparation of thin sections, and Asuka Yamaguchi and Nobuhiro Ogawa for SEM observations. HO is supported by JSPS and FMSP as a research fellow.

Financial support. This research has been supported by the Japan Society for the Promotion of Science (grant nos. JP20J20413, JP20H00200, JP15H02147) and the Cooperative Program (no. 114; 2019) of the Atmosphere and Ocean Research Institute, University of Tokyo.

Review statement. This paper was edited by Jianye Chen and reviewed by two anonymous referees.

\section{References}

Angiboust, S. and Agard, P.: Initial water budget: The key to detaching large volumes of eclogitized oceanic crust along the subduction channel?, Lithos, 120, 453-474, https://doi.org/10.1016/j.lithos.2010.09.007, 2010.

Anthony, J. L. and Marone, C.: Influence of particle characteristics on granular friction, J. Geophys. Res., 110, B08409, https://doi.org/10.1029/2004JB003399, 2005.

Audet, P. and Kim, Y.: Teleseismic constraints on the geological environment of deep episodic slow earthquakes in sub- duction zone forearcs: A review, Tectonophysics, 670, 1-15, https://doi.org/10.1016/j.tecto.2016.01.005, 2016.

Audet, P., Bostock, M. G., Christensen, N. I., and Peacock, S. M.: Seismic evidence for overpressured subducted oceanic crust and megathrust fault sealing, Nature, 457, 76-78, https://doi.org/10.1038/nature07650, 2009.

Berman, H.: Fibrous Brucite from Quebec, Am. Mineral., 17, 313 316, 1932.

Bhattacharya, P., Rubin, A. M., Bayart, E., Savage, H. M., and Marone, C.: Critical evaluation of state evolution laws in rate and state friction: Fitting large velocity steps in simulated fault gouge with time-, slip-, and stress-dependent constitutive laws, J. Geophys. Res.-Sol. Ea., 120, 6365-6385, https://doi.org/10.1002/2015JB012437, 2015.

Bhattacharya, P., Rubin, A. M., and Beeler, N. M.: Does fault strengthening in laboratory rock friction experiments really depend primarily upon time and not slip?, J. Geophys. Res.-Sol. Ea., 122, 6389-6430, https://doi.org/10.1002/2017JB013936, 2017.

Blanpied, M. L., Marone, C. J., Lockner, D. A., Byerlee, J. D., and King, D. P.: Quantitative measure of the variation in fault rheology due to fluid-rock interactions, J. Geophys. Res.-Sol. Ea., 103, 9691-9712, https://doi.org/10.1029/98JB00162, 1998.

Bostock, M. G., Hyndman, R. D., Rondenay, S., and Peacock, S. M.: An inverted continental Moho and serpentinization of the forearc mantle, Nature, 417, 536-538, https://doi.org/10.1038/417536a, 2002.

Calvert, A. J., Bostock, M. G., Savard, G., and Unsworth, M. J.: Cascadia low frequency earthquakes at the base of an overpressured subduction shear zone, Nat. Commun., 11, 3874, https://doi.org/10.1038/s41467-020-17609-3, 2020.

Christensen, N. I.: Serpentinites, Peridotites, and Seismology, Int. Geol. Rev., 46, 795-816, https://doi.org/10.2747/00206814.46.9.795, 2004.

Collettini, C., Viti, C., Smith, S. A. F., and Holdsworth, R. E.: Development of interconnected talc networks and weakening of continental low-angle normal faults, Geology, 37, 567-570, https://doi.org/10.1130/G25645A.1, 2009.

D'Antonio, M. and Kristensen, M. B.: Serpentine and brucite of ultramafic clasts from the South Chamorro Seamount (Ocean Drilling Program Leg 195, Site 1200): inferences for the serpentinization of the Mariana forearc mantle, Mineral. Mag., 68, 887-904, https://doi.org/10.1180/0026461046860229, 2004.

Deer, W. A., Howie, R. A., and Zussman, J.: An Introduction to the Rock-Forming Minerals, 3rd edn., The Mineralogical Society, London, UK, 2013.

den Hartog, S. A. M. and Spiers, C. J.: A microphysical model for fault gouge friction applied to subduction megathrusts, J. Geophys. Res.-Sol. Ea., 119, 1510-1529, https://doi.org/10.1002/2013JB010580, 2014.

den Hartog, S. A. M., Peach, C. J., de Winter, D. A. M., Spiers, C. J., and Shimamoto, T.: Frictional properties of megathrust fault gouges at low sliding velocities: New data on effects of normal stress and temperature, J. Struct. Geol., 38, 156-171, https://doi.org/10.1016/j.jsg.2011.12.001, 2012.

DeShon, H. R. and Schwartz, S. Y.: Evidence for serpentinization of the forearc mantle wedge along the Nicoya Peninsula, Costa Rica, Geophys. Res. Lett., 31, L21611, https://doi.org/10.1029/2004GL021179, 2004. 
Dieterich, J. H.: Modeling of rock friction: 1. Experimental results and constitutive equations, J. Geophys. Res., 84, 2161, https://doi.org/10.1029/JB084iB05p02161, 1979.

Dorbath, C., Gerbault, M., Carlier, G., and Guiraud, M.: Double seismic zone of the Nazca plate in northern Chile: Highresolution velocity structure, petrological implications, and thermomechanical modeling, Geochem. Geophy. Geosy., 9, Q07006, https://doi.org/10.1029/2008GC002020, 2008.

Eberhart-Phillips, D. and Reyners, M.: Imaging the Hikurangi Plate interface region, with improved localearthquake tomography, Geophys. J. Int., 190, 1221-1242, https://doi.org/10.1111/j.1365-246X.2012.05553.x, 2012.

Evans, B. W., Hattori, K., and Baronnet, A.: Serpentinite: What, Why, Where?, Elements, 9, 99-106, https://doi.org/10.2113/gselements.9.2.99, 2013.

Fagereng, A. and den Hartog, S. A. M.: Subduction megathrust creep governed by pressure solution and frictional-viscous flow, Nat. Geosci., 10, 51-57, https://doi.org/10.1038/ngeo2857, 2017.

French, M. E. and Condit, C. B.: Slip partitioning along an idealized subduction plate boundary at deep slow slip conditions, Earth Planet. Sc. Lett., 528, 115828, https://doi.org/10.1016/j.epsl.2019.115828, 2019.

Gao, X. and Wang, K.: Rheological separation of the megathrust seismogenic zone and episodic tremor and slip, Nature, 543, 416-419, https://doi.org/10.1038/nature21389, 2017.

Giorgetti, C., Carpenter, B. M., and Collettini, C.: Frictional behavior of talc-calcite mixtures, J. Geophys. Res.-Sol. Ea., 120, 6614-6633, https://doi.org/10.1002/2015JB011970, 2015.

Guillot, S. and Hattori, K.: Serpentinites: Essential roles in geodynamics, arc volcanism, sustainabled, and the origin of life, Elements, 9, 95-98, https://doi.org/10.2113/gselements.9.2.95, 2013.

Guillot, S., Hattori, K., Agard, P., Schwartz, S., and Vidal, O.: Exhumation processes in oceanic and continental subduction conetxts: a review, in: Subduction zone geodynamics, edited by: Lallemand, S. and Funiciello, F., Springer, Berlin, Heidelberg, Germany, 175-205, 2009.

Guillot, S., Schwartz, S., Reynard, B., Agard, P., and Prigent, C.: Tectonic significance of serpentinites, Tectonophysics, 646, 119, https://doi.org/10.1016/j.tecto.2015.01.020, 2015.

Haines, S. H., Kaproth, B., Marone, C., Saffer, D. M., and van der Pluijm, B. A.: Shear zones in clay-rich fault gouge: A laboratory study of fabric development and evolution, J. Struct. Geol., 51, 206-225, https://doi.org/10.1016/j.jsg.2013.01.002, 2013.

Hirauchi, K., den Hartog, S. A. M., and Spiers, C. J.: Weakening of the slab-mantle wedge interface induced by metasomatic growth of talc, Geology, 41, 75-78, https://doi.org/10.1130/G33552.1, 2013.

Hirth, G. and Beeler, N. M.: The role of fluid pressure on frictional behavior at the base of the seismogenic zone, Geology, 43, 223226, https://doi.org/10.1130/G36361.1, 2015.

Hirth, G. and Guillot, S.: Rheology and tectonic significance of serpentinite, Elements, 9, 107-113, https://doi.org/10.2113/gselements.9.2.107, 2013.

Horn, H. M. and Deere, D. U.: Frictional characteristics of minerals, Géotechnique, 12, 319-335, https://doi.org/10.1680/geot.1962.12.4.319, 1962.
Hostetler, P. B., Coleman, R. G., Mumpton, F. A., and Evans, B. W.: Brucite in Alpine Serpentinites, Am. Mineral., 51, 75-98, 1966.

Hyndman, R. D. and Peacock, S. M.: Serpentinization of the forearc mantle, Earth Planet. Sc. Lett., 212, 417-432, https://doi.org/10.1016/S0012-821X(03)00263-2, 2003.

Ide, S., Beroza, G. C., Shelly, D. R., and Uchide, T.: A scaling law for slow earthquakes, Nature, 447, 76-79, https://doi.org/10.1038/nature05780, 2007.

Ikari, M. J., Marone, C., Saffer, D. M., and Kopf, A. J.: Slip weakening as a mechanism for slow earthquakes, Nat. Geosci., 6, 468472, https://doi.org/10.1038/ngeo1818, 2013.

Ikari, M. J., Carpenter, B. M., and Marone, C.: A microphysical interpretation of rate- and state-dependent friction for fault gouge, Geochem. Geophy. Geosy., 17, 1660-1677, https://doi.org/10.1002/2016GC006286, 2016.

Kawahara, H., Endo, S., Wallis, S. R., Nagaya, T., Mori, H., and Asahara, Y.: Brucite as an important phase of the shallow mantle wedge: Evidence from the Shiraga unit of the Sanbagawa subduction zone, SW Japan, Lithos, 254-255, 53-66, https://doi.org/10.1016/j.lithos.2016.02.022, 2016.

Kawai, K., Sakuma, H., Katayama, I., and Tamura, K.: Frictional characteristics of single and polycrystalline muscovite and influence of fluid chemistry, J. Geophys. Res.-Sol. Ea., 120, 62096218, https://doi.org/10.1002/2015JB012286, 2015.

Kawakatsu, H. and Watada, S.: Seismic evidence for deepwater transportation in the mantle, Science, 316, 1468-1471, https://doi.org/10.1126/science.1140855, 2007.

Kenigsberg, A. R., Rivière, J., Marone, C., and Saffer, D. M.: The effects of shear strain, fabric, and porosity evolution on elastic and mechanical properties of clay-rich fault gouge, J. Geophys. Res.-Sol. Ea., 10968-10982, https://doi.org/10.1029/2019JB017944, 2019.

Kenigsberg, A. R., Rivière, J., Marone, C., and Saffer, D. M.: Evolution of Elastic and Mechanical Properties During Fault Shear: The Roles of Clay Content, Fabric Development, and Porosity, J. Geophys. Res.-Sol. Ea., 125, e2019JB018612, https://doi.org/10.1029/2019JB018612, 2020.

Leeman, J. R., Saffer, D. M., Scuderi, M. M., and Marone, C.: Laboratory observations of slow earthquakes and the spectrum of tectonic fault slip modes, Nat. Commun., 7, 11104, https://doi.org/10.1038/ncomms11104, 2016.

Leeman, J. R., Marone, C., and Saffer, D. M.: Frictional mechanics of slow earthquakes, J. Geophys. Res.-Sol. Ea., 123, 7931-7949, https://doi.org/10.1029/2018JB015768, 2018.

Liu, Y. and Rice, J. R.: Spontaneous and triggered aseismic deformation transients in a subduction fault model, J. Geophys. Res., 112, B09404, https://doi.org/10.1029/2007JB004930, 2007.

Liu, Y. and Rice, J. R.: Slow slip predictions based on granite and gabbro friction data compared to GPS measurements in northern Cascadia, J. Geophys. Res.-Sol. Ea., 114, 1-19, https://doi.org/10.1029/2008JB006142, 2009.

Logan, J. M. and Rauenzahn, K. A.: Frictional dependence of gouge mixtures of quartz and montmorillonite on velocity, composition and fabric, Tectonophysics, 144, 87-108, https://doi.org/10.1016/0040-1951(87)90010-2, 1987.

Logan, J. M., Freidman, M., Higgs, N., Dengo, C., and Shimamoto, T.: Experimental studies of simulated fault gouge and their application to studies of natural fault zones, in: Proc. Conf. VIII 
- Analysis of Actual Fault Zones in Bedrock, U.S. Geological Survey, 305-343, 1979.

Logan, J. M., Dengo, C. A., Higgs, N. G., and Wang, Z. Z.: Fabrics of experimental fault zones: Their development and eelationship to mechanical behavior, in: Fault Mechanics and Transport Properties of Rocks, edited by: Evans, B, and Wong, T. F., Elsevier, London, 33-67, 1992.

Manning, C. E.: Coupled reaction and flow in subduction zones: Silica metasomatism in the mantle wedge, in: Fluid Flow and Transport in Rocks, edited by Jamtveit, B. and Yardley, B. W. D., Springer, Dordrecht, the Netherlands, 139-148, 1997.

Marone, C.: Laboratory-derived friction laws and their application to seismic faulting, Annu. Rev. Earth Pl. Sc., 26, 643-696, https://doi.org/10.1146/annurev.earth.26.1.643, 1998.

Marone, C. and Kilgore, B. D.: Scaling of the critical slip distance for seismic faulting with shear strain in fault zones, Nature, 362, 618-621, https://doi.org/10.1038/362618a0, 1993.

Matsubara, M., Obara, K., and Kasahara, K.: High-VP/VS zone accompanying non-volcanic tremors and slow-slip events beneath southwestern Japan, Tectonophysics, 472, 6-17, https://doi.org/10.1016/j.tecto.2008.06.013, 2009.

Matsuzawa, T., Hirose, H., Shibazaki, B., and Obara, K.: Modeling short- and long-term slow slip events in the seismic cycles of large subduction earthquakes, J. Geophys. Res., 115, B12301, https://doi.org/10.1029/2010JB007566, 2010.

Mizukami, T., Yokoyama, H., Hiramatsu, Y., Arai, S., Kawahara, H., Nagaya, T., and Wallis, S. R.: Two types of antigorite serpentinite controlling heterogeneous slow-slip behaviours of slab-mantle interface, Earth Planet. Sc. Lett., 401, 148-158, https://doi.org/10.1016/j.epsl.2014.06.009, 2014.

Moore, D. E. and Lockner, D. A.: Crystallographic controls on the frictional behavior of dry and water-saturated sheet structure minerals, J. Geophys. Res., 109, B03401, https://doi.org/10.1029/2003JB002582, 2004.

Moore, D. E. and Lockner, D. A.: Comparative deformation behavior of minerals in serpentinized ultramafic rock: Application to the slab-mantle interface in subduction zones, Int. Geol. Rev., 49, 401-415, https://doi.org/10.2747/0020-6814.49.5.401, 2007.

Moore, D. E. and Lockner, D. A.: Talc friction in the temperature range $25^{\circ}-400^{\circ} \mathrm{C}$ : Relevance for FaultZone Weakening, Tectonophysics, 449, 120-132, https://doi.org/10.1016/j.tecto.2007.11.039, 2008.

Moore, D. E. and Lockner, D. A.: Frictional strengths of talcserpentine and talc-quartz mixtures, J. Geophys. Res., 116, B01403, https://doi.org/10.1029/2010JB007881, 2011.

Moore, D. E., Lockner, D. A., Ma, S., Summers, R., and Byerlee, J. D.: Strengths of serpentinite gouges at elevated temperatures, J. Geophys. Res.-Sol. Ea., 102, 14787-14801, https://doi.org/10.1029/97JB00995, 1997.

Moore, D. E., Lockner, D. A., Iwata, K., Tanaka, H., and Byerlee, J. D.: How brucite may affect the frictional properties of serpentinite, USGS Open-File Report, U.S. Geological Survey, 1-14, 2001.

Morrow, C. A., Moore, D. E., and Lockner, D. A.: The effect of mineral bond strength and adsorbed water on fault gouge frictional strength, Geophys. Res. Lett., 27, 815-818, https://doi.org/10.1029/1999GL008401, 2000.

Nagaya, T., Okamoto, A., Oyanagi, R., Seto, Y., Miyake, A., Uno, M., Muto, J., and Wallis, S. R.: Crystallographic preferred ori- entation of talc determined by an improved EBSD procedure for sheet silicates: Implications for anisotropy at the slab-mantle interface due to Si-metasomatism, Am. Mineral., 105, 873-893, https://doi.org/10.2138/am-2020-7006, 2020.

Nakajima, J., Tsuji, Y., Hasegawa, A., Kita, S., Okada, T., and Matsuzawa, T.: Tomographic imaging of hydrated crust and mantle in the subducting Pacific slab beneath Hokkaido, Japan: Evidence for dehydration embrittlement as a cause of intraslab earthquakes, Gondwana Res., 16, 470-481, https://doi.org/10.1016/j.gr.2008.12.010, 2009.

Niemeijer, A. R.: Velocity-dependent slip weakening by the combined operation of pressure solution and foliation development, Sci. Rep.-UK, 8, 4724, https://doi.org/10.1038/s41598018-22889-3, 2018.

Niemeijer, A. R. and Spiers, C. J.: A microphysical model for strong velocity weakening in phyllosilicatebearing fault gouges, J. Geophys. Res., 112, B10405, https://doi.org/10.1029/2007JB005008, 2007.

Noda, H. and Shimamoto, T.: Constitutive properties of clayey fault gouge from the Hanaore fault zone, southwest Japan, J. Geophys. Res., 114, B04409, https://doi.org/10.1029/2008JB005683, 2009.

Noda, H. and Takahashi, M.: The effective stress law at a brittleplastic transition with a halite gouge layer, Geophys. Res. Lett. 43, 1966-1972, https://doi.org/10.1002/2015GL067544, 2016.

Obara, K.: Nonvolcanic Deep Tremor Associated with Subduction in Southwest Japan, Science, 296, 1679-1681, https://doi.org/10.1126/science.1070378, 2002.

Obara, K. and Kato, A.: Connecting slow earthquakes to huge earthquakes, Science, 353, 253-257, https://doi.org/10.1126/science.aaf1512, 2016.

Okamoto, A. S., Verberne, B. A., Niemeijer, A. R., Takahashi, M., Shimizu, I., Ueda, T., and Spiers, C. J.: Frictional properties of simulated chlorite gouge at hydrothermal conditions: Implications for subduction megathrusts, J. Geophys. Res.-Sol. Ea., 124, 4545-4565, https://doi.org/10.1029/2018JB017205, 2019.

Okazaki, K. and Katayama, I.: Slow stick slip of antigorite serpentinite under hydrothermal conditions as a possible mechanism for slow earthquakes, Geophys. Res. Lett., 42, 1099-1104, https://doi.org/10.1002/2014GL062735, 2015.

Okuda, H., Kawai, K., and Sakuma, H.: First-principles investigation of frictional characteristics of brucite: An application to its macroscopic frictional characteristics, J. Geophys. Res.-Sol. Ea., 124, 10423-10443, https://doi.org/10.1029/2019JB017740, 2019.

Oleskevich, D. A., Hyndman, R. D., and Wang, K.: The updip and downdip limits to great subduction earthquakes: Thermal and structural models of Cascadia, south Alaska, SW Japan, and Chile, J. Geophys. Res.-Sol. Ea., 104, 14965-14991, https://doi.org/10.1029/1999JB900060, 1999.

Oyanagi, R., Okamoto, A., Hirano, N., and Tsuchiya, N.: Competitive hydration and dehydration at olivine-quartz boundary revealed by hydrothermal experiments: Implications for silica metasomatism at the crust-mantle boundary, Earth Planet. Sc. Lett., 425, 44-54, https://doi.org/10.1016/j.epsl.2015.05.046, 2015.

Oyanagi, R., Okamoto, A., and Tsuchiya, N.: Silica controls on hydration kinetics during serpentinization of olivine: Insights from hydrothermal experiments and a reactive 
transport model, Geochim. Cosmochim. Ac., 270, 21-42, https://doi.org/10.1016/j.gca.2019.11.017, 2020.

Peacock, S. M. and Hyndman, R. D.: Hydrous minerals in the mantle wedge and the maximum depth of subduction thrust earthquakes, Geophys. Res. Lett., 26, 2517-2520, https://doi.org/10.1029/1999GL900558, 1999.

Peacock, S. M. and Wang, K.: Seismic consequences of warm versus cool subduction metamorphism: Examples from southwest and northeast Japan, Science, 286, 937-939, https://doi.org/10.1126/science.286.5441.937, 1999.

Ramachandran, K. and Hyndman, R. D.: The fate of fluids released from subducting slab in northern Cascadia, Solid Earth, 3, 121129, https://doi.org/10.5194/se-3-121-2012, 2012.

Reinen, L. A., Weeks, J. D., and Tullis, T. E.: The frictional behavior of lizardite and antigorite serpentinites: Experiments, constitutive models, and implications for natural faults, Pure Appl. Geophys., 143, 317-358, https://doi.org/10.1007/BF00874334, 1994.

Reynard, B.: Serpentine in active subduction zones, Lithos, 178, 171-185, https://doi.org/10.1016/j.lithos.2012.10.012, 2013.

Rogers, G. and Dragert, H.: Episodic tremor and slip on the Cascadia subduction zone: The chatter of silent slip, Science, 300, 1942-1943, https://doi.org/10.1126/science.1084783, 2003.

Rubin, A. M.: Episodic slow slip events and rateand-state friction, J. Geophys. Res., 113, B11414, https://doi.org/10.1029/2008JB005642, 2008.

Rubinstein, J. L., Vidale, J. E., Gomberg, J., Bodin, P., Creager, K. C., and Malone, S. D.: Non-volcanic tremor driven by large transient shear stresses, Nature, 448, 579-582, https://doi.org/10.1038/nature06017, 2007.

Rubinstein, J. L., La Rocca, M., Vidale, J. E., Creager, K. C., and Wech, A. G.: Tidal Modulation of Nonvolcanic Tremor, Science, 319, 186-189, https://doi.org/10.1126/science.1150558, 2008.

Ruina, A. L.: Slip instability and state variable friction laws, J. Geophys. Res.-Sol. Ea., 88, 10359-10370, https://doi.org/10.1029/JB088iB12p10359, 1983.

Saffer, D. M. and Marone, C.: Comparison of smectite- and illiterich gouge frictional properties: application to the updip limit of the seismogenic zone along subduction megathrusts, Earth Planet. Sc. Lett., 215, 219-235, https://doi.org/10.1016/S0012821X(03)00424-2, 2003.

Sánchez-Roa, C., Faulkner, D. R., Boulton, C., Jimenez-Millan, J., and Nieto, F.: How phyllosilicate mineral structure affects fault strength in Mg-rich fault systems, Geophys. Res. Lett., 44, 54575467, https://doi.org/10.1002/2017GL073055, 2017.

Schmidt, D. A., and Gao, H.: Source parameters and timedependent slip distributions of slow slip events on the Cascadia subduction zone from 1998 to 2008, J. Geophys. Res., 115, B00A18, https://doi.org/10.1029/2008JB006045, 2010.

Segall, P., Rubin, A. M., Bradley, A. M., and Rice, J. R.: Dilatant strengthening as a mechanism for slow slip events, J. Geophys. Res., 115, B12305, https://doi.org/10.1029/2010JB007449, 2010.

Shelly, D. R., Beroza, G. C., Ide, S., and Nakamula, S.: Lowfrequency earthquakes in Shikoku, Japan, and their relationship to episodic tremor and slip, Nature, 442, 188-191, https://doi.org/10.1038/nature04931, 2006.

Shibazaki, B. and Iio, Y.: On the physical mechanism of silent slip events along the deeper part of the seismogenic zone, Geophys.
Res. Lett., 30, 1489, https://doi.org/10.1029/2003GL017047, 2003.

Shimamoto, T. and Logan, J. M.: Effects of simulated clay gouges on the sliding behavior of Tennessee sandstone, Tectonophysics, 75, 243-255, https://doi.org/10.1016/0040-1951(81)90276-6, 1981.

Siman-Tov, S., Aharonov, E., Sagy, A., and Emmanuel, S.: Nanograins form carbonate fault mirrors, Geology, 41, 703-706, https://doi.org/10.1130/G34087.1, 2013.

Skarbek, R. M. and Savage, H. M.: RSFit3000: A MATLAB GUI-based program for determining rate and state frictional parameters from experimental data, Geosphere, 15, 1665-1676, https://doi.org/10.1130/GES02122.1, 2019.

Song, T.-R. A. and Kim, Y.: Localized seismic anisotropy associated with long-term slow-slip events beneath southern Mexico, Geophys. Res. Lett., 39, L09308, https://doi.org/10.1029/2012GL051324, 2012.

Takahashi, M., Mizoguchi, K., Kitamura, K., and Masuda, K.: Effects of clay content on the frictional strength and fluid transport property of faults, J. Geophys. Res., 112, B08206, https://doi.org/10.1029/2006JB004678, 2007.

Takahashi, M., Uehara, S.-I., Mizoguchi, K., Shimizu, I., Okazaki, K., and Masuda, K.: On the transient response of serpentine (antigorite) gouge to stepwise changes in slip velocity under high-temperature conditions, J. Geophys. Res., 116, B10405, https://doi.org/10.1029/2010JB008062, 2011.

Tarling, M. S., Smith, S. A. F., and Scott, J. M.: Fluid overpressure from chemical reactions in serpentinite within the source region of deep episodic tremor, Nat. Geosci., 12, 1034-1042, https://doi.org/10.1038/s41561-019-0470-z, 2019.

Tembe, S., Lockner, D. A., and Wong, T.-F.: Effect of clay content and mineralogy on frictional sliding behavior of simulated gouges: Binary and ternary mixtures of quartz, illite, and montmorillonite, J. Geophys. Res., 115, B03416, https://doi.org/10.1029/2009JB006383, 2010.

Tesei, T., Harbord, C. W. A., De Paola, N., Collettini, C., and Viti, C.: Friction of mineralogically controlled serpentinites and implications for fault weakness, J. Geophys. Res.-Sol. Ea., 123, 6976-6991, https://doi.org/10.1029/2018JB016058, 2018.

Verberne, B. A., De Bresser, J. H. P., Niemeijer, A. R., Spiers, C. J., de Winter, D. A. M., and Plümper, O.: Nanocrystalline slip zones in calcite fault gouge show intense crystallographic preferred orientation: Crystal plasticity at sub-seismic slip rates at $18-150{ }^{\circ} \mathrm{C}$, Geology, 41, 863-866, https://doi.org/10.1130/G34279.1, 2013.

Verberne, B. A., Spiers, C. J., Niemeijer, A. R., De Bresser, J. H. P., de Winter, D. A. M., and Plümper, O.: Frictional properties and microstructure of calcite-rich fault gouges sheared at subseismic sliding velocities, Pure Appl. Geophys., 171, 2617-2640, https://doi.org/10.1007/s00024-013-0760-0, 2014a.

Verberne, B. A., Plümper, O., de Winter, D. A. M., and Spiers, C. J.: Superplastic nanofibrous slip zones control seismogenic fault friction, Science, 346, 1342-1344, https://doi.org/10.1126/science.1259003, 2014b.

Viti, C.: Exploring fault rocks at the nanoscale, J. Struct. Geol., 33, 1715-1727, https://doi.org/10.1016/j.jsg.2011.10.005, 2011. 